\title{
Uncharted Waters: Family-Making and Trans-Formational Episodic Time in Maggie Nelson's The Argonauts
}

\author{
Eli Jean Dunn \\ San Diego, California
}

Bachelor's of Arts, University of California Irvine, 2011

\author{
A Thesis Presented to the Graduate Faculty \\ of the University of Virginia in Candidacy for the Degree of \\ Master of Arts \\ Department of English \\ University of Virginia \\ June, 2016
}


Trans narratives have seen a massive upswing of interest from both within and outside the queer community in the last several years, with trans characters featured prominently in television, films, and graphic novels. Time Magazine's issue in June of 2014 featured prominent transgender actress and activist Laverne Cox on its cover along with an article titled "The Transgender Tipping Point" which stated that transgender issues were "America's next civil rights frontier" (Steinmetz). Following so quickly on the success of marriage equality, the rise in trans visibility has led some to question whether transgender rights are the next horizon in the struggle for queer rights. While the last year has increased transgender visibility and brought more awareness to the struggles that trans people face on a daily basis (from access to medical care and housing to a lack of protection in the workplace), it has also been a year in which trans people have faced enormous backlash and violence. In 2015 trans people were the victims of the highest number of murders since the collection of such statistics began, with at least 21 trans people murdered in the United States alone, 13 of these within the first six months of the year (Human Rights Campaign). Only a month ago, North Carolina became the first state to require that trans people use the restroom corresponding to the biological sex they were assigned at birth, putting trans people (and especially trans women) into the uncomfortable and potentially dangerous position of being in a private space that does not match their gender identity or presentation. Even more alarmingly, this bill removes the power for localities within North Carolina to set their own non-discrimination laws, opening trans and queer people to the whims of the state government for protection from housing and job discrimination. Similar laws are currently being considered in Illinois, 
Kansas, Massachusetts, Missouri, Mississippi, South Carolina, Tennessee and Wisconsin (National Center for Transgender Equality). Within this environment of increased visibility and increased violence, the stories of trans people become both a catalyst for understanding and change as well as a form of self-preservation, assertion, and strength.

The transgender experience seems to have inherited the foundation of its narrative from a long tradition of storytelling, following the critical path from oral storytelling traditions up into the present moment during which a multiplicity of new and transforming narrative formats tell contemporary trans stories: there is the origin story (childhood), the presentation of a long and complicated middle (the coming out/transition), and the ending (passing or gender fulfillment), which perhaps serves all the more as an arrival for the transgender narrative. But new media forms - in print, film, television, podcasts, web series, and social media - and new genres within these forms, are complicating the traditional architecture of narrative structure, helping to illuminate and recreate the trans narrative at a moment of the utmost urgency. In rethinking some of the foundational structuring elements of narrative, these texts question the embodiment of the text itself, its presentation so to speak, and in seeking to address the challenges of trans-narration, enact the very process of transition itself. Within this evolving and exciting mediascape, a key place to locate this shift can be found in a work that dedicates itself a different kind of transformation - one that labors towards the creation of hybrid genres that emerge in order to translate the theoretical, the experiential, and the affective from one formal system to another. Maggie Nelson's autotheoretical, memoir text The Argonauts defies easy categorization - it is a story of personal experience and family life 
that is also a unyielding expedition into the realms of critical and queer theory, and in this collision of forms it takes up the very concerns at the heart of changing trans narratives.

When popular culture pieces like the Time Magazine article argue that trans rights are the next new frontier, there are two important destabilizing effects that occur: first, there is the implicit argument that trans rights are not LGB rights, and that these categories don't overlap or influence one another (thereby erasing the identity of the lesbian transwoman or the gay transman, or at the very least arguing that their rights or needs as trans people are fundamentally disconnected from those relating to their sexuality) and secondly, it makes the assumption that the rights of those within the LGB category are solved, such that now the community can move on to the next issue. Now that the white, middle-class homosexual couple has been institutionalized, folded into heterosexual paradigms of marriage and monogamy, the next frontier would be to tackle trans issues. Or as Tulia Thompson states it, "We are undoubtedly witnessing a shift in queer politics that is entrenched in the politics of late capitalism, where the hegemonic subjective of white, middle-class gays and lesbians in the first world are overly disaggregated from those of us who are still variously 'queer' outsiders" (85). Is the monogamous gay or lesbian couple then stripped of their ability to destabilize the heterosexist social constructs of which they may find themselves a part? What about the couple which may pass as straight, owing in part to one of the partners who is a stealth trans person?

Much of Nelson's work takes up these very issues of normativity, questions of radical embodiment, radical living and the power or lack of power that comes with being 
forced to define oneself in terms of polar opposites of any kind. Indeed the struggle against homonormativity, which Lisa Duggan has defined as "a politics that does not contest dominant heteronormative assumptions and institutions - such as marriage, and its call for monogamy and reproduction - but upholds and sustains them while promising the possibility of a demobilized gay constituency and a privatized, depoliticized gay culture anchored in domesticity and consumption" (179) takes an interesting and defining turn within The Argonauts. Once again, Nelson's work takes up a powerful and important intersectional moment - Nelson describes it as a

historical moment in which conservative anxiety and despair about queers bringing down civilization and its institutions (marriage, most notably) is met by the anxiety and despair so many queers feel about the failure or incapacity of queerness to bring down civilization and its institutions, and their frustrations with the assimilationist, unthinkingly neoliberal bent of the mainstream GLBTQ+ movement, which has spent fine coin begging for entrance into two historically repressive structures: marriage and the military. (26)

The Argonauts takes up questions of what it means to be a queer within this defining moment in queer history, a moment in which the community's political movements are in transition and questions of assimilation, hetero, and homonormativity create conflicting priorities within these movements and further complicate the formulation of stable queer and trans identities. In doing so, The Argonauts uses complex and definitively queer 
forms of time that focus on rebuilding, recreating, and reformulating one's relationship to a heterosexual culture.

In what follows I want to track the movements that Nelson's work contributes to the immersion of the new trans narrative, analyzing the revelatory aspects of Nelson's hybrid work as it focuses on 'trans' in all senses. The Argonauts is deeply invested in embracing this Latin root, in the work of carrying across, over, or beyond both in its structural and narrative commitments. Broadening this discussion, I want to briefly consider the implications of structural moves within The Argonauts for reading the sudden deluge of transgender narration that has perhaps been most culturally visible in recent television shows like Orange is the New Black and Transparent. Working with a text like The Argonauts, that challenges our critical categories, as a space to trace out some of the occlusions and narrative impasses of a transgender narrative aesthetic that is also a politics, allows us to broaden our frameworks of representation, translating and trans-'genre'-ing them until they are unrecognizable.

In the first section of this paper, I address the the ways that The Argonauts situates family-making and the perception of reproduction outside the spectrum of heteronormativity to radical queerness. I argue that Nelson's text refuses the strict association of family, tradition, and maternity with heteronormativity, instead making an argument for the fundamentally radical act that is creating one's own queer family of various relationships and bonds. I also detail the ways that Nelson's own text is an example of queer family-making not only in its commitment to representing the detailed process of coming together in various ways (both biological, romantic, parental, and 
platonic) but in its association of the author's voice with a multi-generational and multi-genre chorus of other writers, theorists and thinkers. I continue in the following section to interrogate the ways in which this same employment of various theorists allows Nelson to further complicate her narrative timeline, which already moves forward and backwards dramatically through time from one paragraph to another. I argue that through The Argonauts' timeline, Nelson is able to challenge traditional narrative temporality, widen the scope of experiences that are allowable within a formulation like Jack Halberstam's 'queer time' and demonstrate the complicated relationship between time and identity-building both within and outside the text. The final section looks more specifically at Nelson's husband Harry and the way that the text's commitment to openness and becoming, to existing between categories, manifests itself in his story. I claim that Harry's experiences within the nonlinear time frame of The Argonauts amounts to an episodic medium that is more in line with television than traditional literary narratives. This episodic timeline allows Nelson to more accurately portray (in both form and content) the labor involved in creating and maintaining a gender identity that lies somewhere between cisfeminine and transmasculine. In my concluding thoughts I briefly question the ways in which we might read popular television trans narratives in light of the techniques and concerns brought to the fore by The Argonauts.

\section{Theorizing the Queer Family and Familiarizing the Queer Theoretical}

Nelson's autotheoretical text concerns itself from the beginning with the formation of family, and stresses the importance of loving queer relationships. The 
Argonauts' main narrative arc explores Nelson's pregnancy and the birth of her son Iggy in parallel with her husband Harry's transition. Harry's transition to a more masculine embodiment and Nelson's simultaneous pregnancy (which marks her as perhaps even more female or at least marks her with a different form of femininity), lead Nelson to interrogate the formation of her family, and its place within queer theoretical discourse. Is there something essentially heteronormative about the production of family? And if not, why is the queer family absent within much of queer theoretical discourse? Nelson contends that queers have a tradition of making their own families (that include a multiplicity of types of people and relationships) and that her pregnancy is itself a continuation of this tradition. Along the way, The Argonauts incorporates the interjection of many voices straight into the text, making the very text a form of queer family-making itself.

Early in The Argonauts, Nelson relates the story of a friend who comes over to the house that she shares with Harry for coffee. The friend pulls down a mug which was given to Nelson by her mother, one "of those mugs you can purchase online from Snapfish, with the photo of your choice emblazoned on it" (12). The photo is of Nelson and her family, participating in a Christmas tradition of going to see a production of the Nutcracker: "In the photo I'm seven months pregnant with what will become Iggy, wearing a high ponytail and leopard print dress; Harry and his son are wearing matching dark suits looking dashing. We're standing in front of the mantel at my mother's house, which has monogrammed stockings hanging from it. We look happy" (13). The story sets a familiar enough scene of family-making, one in which the next generation of the 
family continues the holiday traditions of the previous generation, or as Nelson puts it, "participating, or acquiescing into participating, in a long tradition of families being photographed at holiday time in their holiday best" (13). But in the case of Nelson and her family, the gift of a photo mug that represents this tradition makes her feel uncomfortable. She says that she was "horrified" when she received it, and the friend who has come over for coffee remarks upon seeing it that she's "never seen anything so heteronormative" in "all her life" (13). What is it about the traditions of the family, or the specific traditions represented within this photo that scream heteronormativity to the friend who comes over? After all Nelson herself certainly wasn't horrified at the time the photograph was taken, on the contrary, she was happy. Happy to be pregnant, dressed up, participating in a holiday event, being with the family that she helped to create.

As she often does over the course of The Argonauts, Nelson asks these same questions of herself, trying to logically and theoretically explain what it is about the reproduction of this photographed moment that so bothered her and occasioned the comment by her visitor. How can she frame her lived experience of family in a way that doesn't disregard her commitment to queer and feminist theory, and yet, look happy to be with her family, seemingly heteronormative or not. She asks:

But what about it is the essence of heteronormativity? That my mother made me the mug, in part to indicate that she recognizes and accepts my tribe as family? What about my pregnancy - is that inherently heteronormative? Or is the presumed opposition of queerness and procreation (or, to put a finer edge on it, maternity) more a reactionary 
embrace of how things have shaken down for queers than the mark of

some ontological truth? (13)

Nelson's project is not satisfied with the presentation of her friend's remark, nor with the presentation of her own immediate feelings regarding the event. Instead, she repeatedly turns to theoretical approaches to understand, contextualize, and better capture her own life.

Nelson answers her questions about whether there is something heteronormative about pregnancy or about her family moment not just by continuing to lean on her own experiences but by turning to Judith Butler and Jacques Lacan: "When or how do new kinship systems mine older nuclear-family arrangements and when do they radically recontextualize them in a way that constitutes a rethinking of kinship" she asks, using Butler's words, “How can you tell; or rather who’s to tell?” (15). Nelson appeals to Butler to frame her own questions, to situate her interrogation about the heteronormality (or not) of her family within a theoretical debate that extends beyond the boundary of her individual experiences. Even within Butler, however, there are two choices, either one adopts the heteronormative frameworks that model relationships and families or one revolutionizes them (even if this revolution comes through their adoption by non-normative families). Nelson's use of Lacan on the other hand, changes and opens the question to allow for more than these two responses: "But any fixed claim on realness, especially when it is tied to an identity, always has a finger in psychosis. If a man who thinks he is king is mad, a king who thinks he is king is no less so" (15). Lacan's words supplement Nelson's reading that there is more than just the queer or the 
heteronormative, there are identities, embodiments, and yes, families that fall between on that spectrum. In this way, she comes to much the same conclusion as Weiner and Young who claim:

What is the queer bond between the urban 'assimilationist' lesbian housewife and the radical queer outside the charmed circle of sexual normativity? We question the enduring value of any binary that situates gay and lesbian on one side and queer on the other. As long as we continue to inhabit a homophobic social-symbolic order, there will remain something queer about the most ostensibly 'homonormative' iterations of gay and lesbian desire; similarly, there is no 'radical' queer formation that escapes all will to normativity. (229-230)

Wiener and Young, like Nelson, thread the delicate and yet critically important space between the alternatives that Butler presents - the seemingly homonormative gay or lesbian family is never completely assimilated into a cisheteropartriachal system, neither is the non-normative queer immune to the same assimilating forces. Nelson's own family destabilizes the categories of gender, family-making, and sexuality, after all, her husband does not identify as either male or female, one of her sons was conceived with a sperm donor, and the other son is biologically Harry's to whom Nelson is stepmother. As such, Nelson's family may be the very picture of non-traditional, and yet even her family, by virtue of its being family at all (and perhaps by virtue of Harry's passing as male), can seem traditional. It takes the combination of theory and personal reflection to begin to get 
at that space between the radical and the normative, and to begin to widen this space for a family like Nelson's.

The need to make space for the queer family doesn't always come up through Nelson's personal experiences, she also demonstrates the way other queer artists have grappled with family-making, situating her own narrative within a chorus of other familial formations. The art show Puppies and Babies that Nelson views and presents to her reader is one of those voices. An "anarchic, colorful, blissed-out collection of snapshots" by A.L. Steiner, the photographs feature a multiplicity of different types of families (70). From one photo in which "a naked woman spoons two dogs" to another in which "Alex Auder, pregnant and in leather Dom gear, pretends to give birth to an inflatable turtle.” (71), Nelson sees this proliferation of family types, of expressions of family-making, as something simultaneously subversive and normative, something both ecstatic and natural. She argues that even some of those in the installation who don't identify as queer are in, fact, queered by their appearance in the photographic collection: I mean to say that it partakes in a long history of queers constructing their own families - be they composed of peers or mentors or lovers or ex-lovers or children or non-human animals - and that it presents queer family-making as an umbrella category under which baby making might be a subset rather than the other way around. (72)

Puppies and Babies reminds Nelson, and the reader as well, that Nelson's own experience making a family is both part of a long heterosexual and a long queer tradition. Within this tradition, Nelson's pregnancy is both radical and normative, the openness of 
Dunn 12

the text, and of individual experience, trumping the common wisdom that family is innately heteronormative. Steiner's collection captures all forms of queer bodies and queer familial intimacies, ones that would seem non-normative in straight culture, "Indeed," Nelson muses, "one of the gifts of genderqueer family making - and animal loving - is the revelation of care taking as detachable from - and attachable to - any gender, any sentient being" (72). Family making of any kind seems to Nelson unidentifiable as either a radical or a heteronormative step, and queer family-making (whether biological/physical or not) is even more so.

However, Nelson's musings on family don't merely include her direct discussions of family-making, they also include the many of voices that she interacts with over the course of The Argonauts. The margins serve as a place for Nelson to reference the ideas of theorists from Judith Butler, Gilles Deleuze and Michel Foucault, literary critics from Susan Fraiman to Eve Sedgewick to Leo Bersani, writers from Anne Carson to Allen Ginsberg without having to disrupt the flow of the text, their names merely stand as silent sentinels to the side of the paragraphs where Nelson wrestles with integrating their thoughts into her personal reflection. Sometimes their theoretical assertions are highlighted within the text in italics as in the example of both Butler and Lacan referenced above. This format choice allows Nelson more freedom to adopt various theorists as a part of her thought process without breaking the intimate, confessional feel of the text with formal attribution and yet still makes sure that the reader can identify those that Nelson is in conversation with if they so choose. In incorporating these names, Nelson has also crafted a text that has a distinct conversational feel. For example, in a 
section of The Argonauts which discusses the wide range of identifications, embodiments, and attitudes towards gender that fall under the umbrella term 'transgender' Nelson's voice is joined over the course of three paragraphs with the voices of Beatriz Preciado, Lucille Clifton, Deleuze and Guattari and Judith Butler (53). Nelson even makes use of Harry's voice directly in italics over the course of the work, and his name accompanies those theorists as one among the many within the margins. In doing so, Nelson sets Harry's textual authority or level of insight into her reflection at the same height and importance as say, Foucault, but she also highlights the level of her intimacy with the theorists by placing them on the same personal level as her husband.

Overlapping voices - poetic, narrative and theoretical - situate Nelson's voice not as the sole authority, but as part of a larger, almost familial, chorus:

"the stable of people I have come to think of as my sappy crones (except that they aren't really sappy, and they're not really crones). You've already met some of them. For a while I was calling them my good witches, but that wasn't quite right. If it weren't such a lengthy moniker I might call them 'the many gendered-mothers of my heart' (57).

Nelson's connection with these mothers is a textual form of queer family-making in much the same way as the exhibition Puppies and Babies displays visually in its photographs. This range of voices, a discussion between thinkers from past and contemporary moments, not only situate Nelson's voice among those of other great writers, but makes the queer theoretical familial at the same time as the book concerns itself with making the queer family theoretical. Just as some of the subjects of Steiner's 
photographic collection may not be queer, but are queered by their association with the queer tradition of family-making displayed in the collection, so these theorists and writers become a part of Nelson's extended family through their use in describing and helping to illuminate Nelson's personal life experiences. Nelson's theoretical family plays as important a role within The Argonauts as her personal family, and this intimacy with theory is part of what makes The Argonauts so dynamic. The conversation that occurs over the course of The Argonauts is remarkable not only for its effect on Nelson's presentation of family, and the opening of queer families to include even the seemingly heteronormative, but these voices also aid Nelson in breaking open traditional timelines.

\section{The Non-Linear Narrative and Opening Queer Time}

The Argonauts' relationship with theorists from different ages, and their insertion into discussions of different points within Nelson and Harry's lives serves not only to contribute to the text's polyvocality but also to displace or disorganize a traditional flow of narrative time within the work. Theorists or writers from completely different time periods can comment on the same topic within the same paragraph in The Argonauts, and the effect of this is to remove both their comments and the experience on which they comment from time. However, this is not the only way in which the narrative time structure of The Argonauts serves to help disrupt and destabilize opposing categories, making space for Nelson and Harry to inhabit the liminal areas between binaries. Nelson's refusal of chronological structuring throughout the text helps to resist the 'before' and 'after' trope that structures many queer and trans memoirs. Rather than 
allowing the creation of Nelson's queer, theoretical, biological, and chosen family to be presented in a temporality that emphasizes the 'after' as a period of stasis, the ultimate outcome of change, The Argonauts juxtaposes scenes from vastly different perspectives and experiences along the narrative's timeline, blocking any one moment from having a privileged viewpoint on the preceding or following life events. José Muñoz has claimed that "Queer restating of the past helps us imagine new temporalities that interrupt straight time" (Muñoz 171) and this process within The Argonauts creates a new simulation of queer time, one that prioritizes becoming and rejects stable categories.

Nelson's commitment to temporal instability seems at first glance to locate her within Jack Halberstam's formulation of a specifically queer time that produces "alternative temporalities by allowing their participants to believe that their futures can be imagined according to logics that lie outside of those paradigmatic markers of life experience - namely birth, marriage, reproduction, and death" (In a Queer Time and Place 2). Within this scheme, queer time is a mode of approaching time nonlinearly. There is no so-called natural progression from one mode of living to another based on traditional time-marking experiences. Nelson's nonlinear narrative would seem to conform to such a conception of time, one that characterizes queer lives by setting them in almost direct opposition to heteronormative forms of narrative temporal markers. “"Queer time' is a term" Halberstam continues, "for those specific models of temporality that emerge within postmodernism once one leaves the temporal frames of bourgeois reproduction and family, longevity, risk/safety, and inheritance" (In a Queer Time and Place 6). Halberstam argues that this type of queer time opens the possibility for different 
forms of reproduction and time-marking, and that it dignifies and accounts for subcultural lives. The common conception of queer time is that queer people are living within a time that is culturally perceived as an extended adolescence (In a Queer Time and Place 5). However, the content of Nelson's book refutes easy assimilation of her text into this formulation of time. After all, as previously discussed, a large majority of her book surrounds, theorizes, and contends with attempts to understand queer family-making. There is also a sizable chunk of The Argonauts devoted to telling the story of the Nelson and Harry's attempt to get married in California immediately before the passing of Proposition 8 (which temporarily blocked couples the state perceived to be of the same sex from entering into marriage). If Nelson spends such time dealing with the very same life events that queer time purports to reject in favor of new possibilities for lived experience, can her memoir still maintain its commitment to the queer?

Nelson attempts to answer this charge by refusing the question, arguing instead that "nothing we do in this life need have a lid crammed on it" and "no one set of practices or relations has the monopoly on the so-called radical, or the so-called normative” (Nelson 73). Instead, Nelson crafts her own relationship, and Harry's relationship, to both narrative and lived time within The Argonauts as one that relies on the instability of time in order to emphasize that there is no completed self - that family, gender, and relationships are always changing. Change here is not progressing from one fixed category or point to another, but instead a state of constant mutation and flux based on a variety of combined, remembered, and reconstructed experiences. On the other hand, it is clear that Nelson's work does not disregard the power of specifically queer 
formulations of time. Indeed, there is very little about the narrative timeline of The Argonauts that does follow traditional models, and that very disruption of time is what allows Nelson the room to emphasize the way her real, lived, queer life is not categorizable either within strict heteronormative or radical queer frameworks.

While the overall narrative progression of The Argonauts follows a chronological arc from the beginning of Nelson's relationship with Harry to the birth of Iggy, the multiple narrative divagations complicate a smooth linear timeline. For one thing, though a vast majority of The Argonauts discusses the time during which Nelson was pregnant with Iggy, much of her musing on child-raising and the stress put on parents, comes from her vast learned experience on the subject after the birth of Iggy. This commenting back on her pregnancy from the vantage of a mother of a child several years old doesn't seem revolutionary in itself, but even her comments on the subject don't seem to be presented to the reader in a chronological order. Rather, Nelson's text is structured more through a free-association of ideas than a linear timeline. As early as around a third of the way through The Argonauts, Nelson takes on the topic of Iggy's bodily autonomy, and feeling whether or not she had a right to touch him:

“no matter how well you feel you've gotten to know your baby's rhythm in utero, the baby's body is still a revelation...I was so in awe of Iggy's fantastic little body that it took a few weeks for me to feel that I had the right to touch him all over...I wanted to attend to Iggy, but I didn't want to ambush him...until one day I realized, he's my baby, I can - indeed I must - handle him freely and ably...I delight in pouring water over his head with 
a toy boat full of holes, wetting his blond curls, matted with butter from a plate he recently made into a hat." (42)

Within this short piece of the story, several things are happening in quick succession: Nelson begins the paragraph talking about feeling as if she understood the way that Iggy's body was separate from her own, his rhythms uniquely his own, even while he was still in the womb. Then the paragraph fast forwards past the experience of birthing a baby and to the immediate time after birth in which Nelson feels that touching Iggy would be a violation of the personhood signified by his having come into his own embodiment, an embodiment new to the both of them. Finally, the meditations on Iggy's body and Nelson's ability to touch and care for him ends at the moment he is an old enough baby to sit up in the bath, having water poured over his head to wash out the food that he has messed in it. It isn't Iggy's chronological growth that structures the section, but rather the evolution of Nelson's feeling towards the idea of his "physical autonomy" (42).

The lack of regard for stable narrative time is compounded when the passage discussing Iggy's body is viewed in the context of those paragraphs that surround it. The previous narrative section is one in which Nelson is attending a presentation in 1998, "just a few weeks" into her "graduate career" (39) and the following passages deal with Iggy's first year of life, Nelson's consultation of baby books before and after he is born, breastfeeding, writing of one's beloved, and the completion of the first draft of the text itself. Iggy's actual birth is only recorded a mere ten pages before the end of The Argonauts. When he is born, it is in the present tense, even though so many of the 
passages before have made it clear that Nelson is writing from the point of view of a mother with a child rapidly growing out of babyhood: "And then, suddenly, Iggy. Here he comes onto me, rising. He is perfect, he is right. I notice he has my mouth, incredible. He is on me, screaming" (133). Committing to such a time scheme within The Argonauts allows for each of Nelson's experiences to stand almost autonomously. Iggy's body can be a subject on its own, traced through Nelson's experience and access to theory over the course of several paragraphs - his body does not need to have been born yet to be an object of interest.

It is not just the narrative that follows Nelson's pregnancy and the birth of Iggy which are chronologically complicated subjects within The Argonauts. Even Nelson's rendition of Harry's life does not run a clear course from beginning to end. For example, Nelson tells one of her most uninterrupted narratives of Harry towards the end of the book, and even these three pages jump dramatically through time over the course of a few discrete paragraphs: the section begins with the time following Harry's mother's death, jumps to Harry's birth, then to a New York Times piece written about him in 2008, to his search for his birth parents in his early thirties and finally to his sobriety at twenty-three (Nelson 136-138). The structuring movement of these sections is not chronology but an emphasis on a concept important to trans a gender nonconforming individuals, naming. First Harry was Wendy Malone, "perhaps you were Wendy Malone for but minutes, or hours" before he is adopted at three weeks "whereupon [he] became Rebecca Priscilla Bard” (136). Nelson laughs over Harry’s attempts to nickname himself Butch in college, and then tells how Harry became Harriet and finally Harry. The next section follows and 
Dunn 20

expands on this emphasis on naming by discussing how Harry couldn't appear in the pages of the New York Times unless he "chose Mr or Mrs" (137). Nelson tells the reader that Harry opted for the female form but that this choice wasn't a straightforward one: "You'd been waiting your whole life for this kind of recognition; now here it was, but with this price" (137). The emphasis on naming becomes naming one's parents when Nelson discusses Harry's search for his birth mother, and emphasizes how monumental it was when his mother told him the name of his father. Finally, his commitment to sobriety at twenty-three is the case of the name being importantly unstated. Nelson never calls Harry an alcoholic, but the word names even in its absence: "You had your last drink at twenty-three" she says, the simple sentence surrounded by white space that makes it stand out even amongst the multitude of small stories, "You already knew" (139). In the case of Harry, this switching from one period of his life to a dramatically different one not only emphasizes the range and richness of his life, it gestures to the fact that his physical transition into a more masculine gender presentation and embodiment has not been the only, nor maybe even the most monumental, change over the course of his lifetime. Harry has, like the rest of us, like Nelson and like Iggy, been a work in progress both within The Argonauts and outside of it.

\section{Episodic Trans Time and Gender Becoming}

While Harry's bodily transition is not the only experience that structures Nelson's portrayal of him, his relationship to gender throughout the work is one of the topics that brings Nelson back to productive sections delving into gender and heteronormativity. His 
transition has consequences for the family that he and Nelson are building together, and his presentation as male can lead to misrecognition as to the the meaning of their family when they are viewed in a public space. On the other hand, Harry's physical and emotional transition helps Nelson interrogate gender and illustrate the particular relationship that gender nonconforming trans people like Harry have to normative gendered interaction. Even more crucially perhaps, Harry's complex exchanges with a gender binary that he rejects continues the rest of the text's attempts at refusing categories (categories of family, categories of time). His interactions with others over the course of The Argonauts shows that living in a state of constant becoming within a system that demands some form of gender stability requires not only work and strength of spirit, but an ability to reconfigure one's relationship to gender with each new misrecognition. Nelson's relationship with Harry and his transition is one of the guiding threads throughout the work and through it Nelson illustrates a particular and complicated relationship between the book's structural presentation of narrative time and the representation of trans identity.

Harry's transition is often inscribed in the text as a kind of parallel to Nelson's pregnancy, both are experiencing radical bodily change at the same moment in their relationship and these changes have a real effect on the ways that they view their physical and emotional identities and the way they're described within the text. At the very same time that Nelson's pregnancy is beginning to show, she and Harry make the trip to Fort Lauderdale so that he can undergo top surgery. Nelson calls 2011 "the summer of our changing bodies" and notes that their transitional timelines are almost in sync: "Me, four 
months pregnant, you six months on T" (79). After the surgery, they spend some extra time in Florida so that Harry can recover before they head home. Even their experiences of feeling ill or out of sorts in their transitional bodies is described in a parallel way: "On our third day, we drove to the second-largest mall in the world and walked for hours, even though I was dizzy and exhausted from early pregnancy and the suffocating heat and you were just barely over the lip of the Vicodin" (80). This parallelism between their changing bodies in the text has several interesting consequences for The Argonauts - the first of these is that it portrays the two changes as equal, as natural consequences of becoming, of family and identity-making that affect the body and transform one's felt relationship to it. In this context, Harry's transition, which may seem a radical move of dramatic gender change is domesticated and naturalized, surrounded by the same language of wholesomeness and beauty that we use to talk about pregnancy. The reverse is true as well. Thinking of Nelson's pregnancy as the same kind of dramatic personal transformation as the gender reassignment surgery that Harry undergoes helps to underline the radical, powerful metamorphosis that is pregnancy. In linking Harry's transition to Nelson's pregnancy, Nelson does more than just recontextualize both these transformations, she begins to fundamentally break down the categories that shape them, continuing the text's commitment to becoming, and to making a home of the space between categories (between radical and normative, between natural and unnatural, between before and after, between female and male).

It is necessary for The Argonauts' commitment to becoming and the nonradical to also incorporate the theoretical into her discussions of gender. Queer theorists often face 
a backlash against their supposed lack of connection to real gender as it is lived. In positioning her life alongside the words of theorists and writers, Nelson clearly shows the co-structuring of experience that the personal and the theoretical have had on her own perceptions of queerness and gender. As Gayle Salamon puts it in her book Assuming a Body: Transgender and the Rhetorics of Materiality:

How we embody gender is how we theorize gender and to suggest otherwise is to misunderstand both theorization and embodiment. To offer the category of real gender in an attempt to discipline what are perceived as the excesses of theoretical gender is to domesticate gender as it is lived and to deny its considerable complexity, which often outpaces our language to describe it (Salamon 71-72).

That is to say that to know one's gender and its place within the larger gender binary/ecosystem is to theorize that gender as well as embody it. Trans people, especially nonbinary trans people, are confronted with the philosophical and cultural constructs that maintain this binary system daily. To operate within that world with any confidence in one's felt relationship to gender means understanding the system within which that felt sense operates (or is ostracized).

The Argonauts' structure also reifies Harry's commitment to staying outside the gender binary as a place of identity that affords him a sense of belonging and power. Harry's negotiation of the space between the gender poles is accomplished with many of the same structural elements that have aided in hollowing-out categories of radical and non-radical when it comes to the representations of family and time. The individual 
paragraphs that make up The Argonauts don't merely act as a technique with which to alter the traditional narrative timeline. By moving backwards and forwards, they simulate a televisual, episodic experience of time that continues the text's commitment to becoming as a primary mode of experience. Or as Nelson describes it: "it is the binary of normative/transgressive that's unsustainable, along with the demand that anyone live a life that's all one thing" (Nelson 74). The episodic structure of The Argonauts mirrors that of traditional television sitcoms, in which recurring characters and attitudes become more natural to the audience over time by virtue of their repetition. Amy Villarejo argues in her book on queer television that televisual time involves the viewer and that it works differently on a fundamental level than, say, the temporality of a novel. Televisual time is "a flow of time across episodes, in which the spectator will bring habits, traits, appearances, histories, past actions, familial associations, relationships, and whatnot across the dead time that composes the intervals between episodes" (Ethereal Queer 31). The space between episodes serves as a place for the viewer to regroup, to relate their own life experiences, histories, and values to those of the television show as well as reproduce and reconstruct the historical facts of the previous episode before bringing those to their interaction and consumption of the next one.

While Villarejo calls the time between the episodes "dead time" her argument would seem to suggest that this time is anything but dead. Instead, the time between episodes, or in the case of The Argonauts, the white space between paragraphs, is a chance for the reader to do some of the narrative heavy-lifting; they carry over the experience of the previous episode to the new one, doing the mental work of integrating 
Dunn 25

the lessons, attitudes, or familiarities into their worldview before watching the next. The watcher, or in our case the reader ${ }^{1}$, uses the episodic breaks to create and carry over a personalized and relational history of association with the text to the next portion of the narrative. The time between episodes, therefore, acts as a place of repositioning and reconstruction, one in which the viewer must formulate their relationship to the last section of the narrative so that the narrative can continue to operate successfully.

The episodic narrative structure of The Argonauts and its dedication to troubling cisheteropartriachal conventions does more than just establish a queer time in contrast with the seemingly conventional topics of family and reproduction. The episodic structure closely mirrors the very experience of identity production, especially trans identity formation. The trans person, more specifically the nonbinary or genderqueer trans person, lives a life constantly between the poles of the gender binary that structures our experiences which forces them to reconstruct their relationships to gender with each and every interaction. The Argonauts, takes pains to illustrate the complicated relationship that Harry, who is "happy to identify as a butch on T" (53) has to the gendered assumptions of the world around him in various real, lived situations:

${ }^{1}$ This isn't to say that the watcher of television and the reader of texts are fundamentally the same, or that the primary mode of each media are rendered indistinguishable in this case. Obviously, televisual content requires unique investments, contexts, and interactions - but at its core, the act of television-watching is still the consumption of narrative. While the primary communicative method of television may be visual, and that of books like The Argonauts may be textual, I argue that The Argonauts' investment in creating an episodic structure brings these two closer together, rather than further apart in a way that is useful in comparing the forms of media in which trans stories are most often told. 
When we take Iggy to the doctors together now, the nurse always says how happy it makes her to see a father helping out with a baby. I'm certainly doing their team a lot of favors, you mutter. Conversely, there's at least one restaurant we don't go to anymore because the waiter had a Tourette's-like addiction to calling everyone in our family 'ladies' every time he so much as deposited a bottle of catsup at our table. (137)

Nelson illustrates in this section the way that the world makes assumptions about Harry's gender - in some situations he passes as male and certain values or conventions are associated with his masculinity (e.g. he's different from many fathers that don't involve themselves in the doctor appointments of their infants). In other situations however, he is read as female and consequently treated differently (e.g. he's grouped in with Nelson under the category 'ladies'). In neither situation is Harry entirely comfortable. When it is assumed that he is male, he tells Nelson that he is doing favors for "their team" distancing himself from inclusion in the male group. On the other hand, his level of discomfort at being read as a woman at the restaurant they frequented leads the family to find somewhere else to dine. In each situation the perception doesn't quite fit the reality of Harry's relationship to gender:

I'm not on my way anywhere, Harry sometimes tells inquirers. How to explain, in a culture frantic for resolution, that sometimes the shit stays messy? I do not want the female gender that has been assigned to me at birth. Neither do I want the male gender that transsexual medicine can furnish and that the state will award me if I behave in the right way. (53) 
Harry refuses the traditional categories of male and female, seeing them as acting upon him - the feminine "assigned to" him and the masculine as something that the a governmental system could potentially "award" him². Importantly, Harry sees these interactions as thrust upon him, he is a receiver of misrecognition, not an actor in creating that misrecognition.

The multitude of microaggressions Harry faces in a binary culture means that he has to do the work of structuring his reactions to being included (wrongly) in each group, and reformulate them according to his felt relationship to gender and his history of passing or not in various situations. In doing the work of creating his relationship to the narratives pressed upon him with regards to his gender Harry does much of the same work of historical positioning as the watcher or reader of episodic media must in order to craft meaning. Halberstam claims:

Queer genders profoundly disturb the order of relations between the authentic and the inauthentic, the original and the mimic, the real and the constructed...there are no true accounts of 'passing lives' but only frictions, and the whole story turns on the production of counterfeit realities that are so convincing that they replace and subsume the real. (45)

${ }^{2}$ It is worthwhile to note that the second set of statements in italics in the longer quotation above is Nelson not quoting Harry (as in the first italic section) but instead excerpt from Beatriz Preciado's Testo Junkie: Sex, Drugs, and Biopolitics in the Pharmacopornographic Era. The quotations' respective authors are noted within the margin of the text though not reproduced here. While the second statement does not represent Harry's words, Nelson's association of the two speakers within the same sentence implies that they have similar feelings as to the representation of their genders, and shows that there are others than just Harry who feel society doesn't properly embrace a range of gender expressions. 
If queer genders such as Harry's trouble the relationship between fixed categories of reality and authenticity, then their action upon those categories (by virtue of being between them) places them at the same crossroads of categorical refusal as the televisual narrative: "television lodges itself in the spectator, confusing the distinction between what is imaginary and what is real; identification is a process that, strictly speaking, happens with television, not with its contents, yet who can tell the one from the other?" (Villarejo 54) For Harry, this means residing within a state of constant becoming, between one narrative and the other, doing the work of creating his own embodiment, his own gender identity, and his own story.

Harry is the trans person who resides within the "dead space" that Villarejo describes. If television is, as Villarejo asserts, a process of shuttling "between the macro industrial and the micro individual" and "a machine that produces its value from that very movement" then Harry's experience directly parallels that movement (Villarejo 154). His day-to-day experience require so much refocusing, from the small individual moments of misgendering microaggressions to the larger picture of his relationship, the nonbinary trans relationship, to gender and the public perception of that gender. Harry's experience as a person between normative genders, as "a butch on T" is an experience of constantly building, becoming, and reaffirming one's identity based on a history of small narratives throughout the text in which he feels more spectator than participant. As Salamon phrases this labor:

To affirm a materiality - or, to be less abstract, to insist on the livability of one's own embodiment, particularly when that embodiment is culturally 


\section{Dunn 29}

abject or socially despised - is to undertake a constant and always

incomplete labor to reconfigure more than just the materiality of our own

bodies. It is to strive to create and transform the lived meanings of those

materialities. (Assuming a Body 42)

In other words, one has to reconfigure not just the external signs of gender (i.e.

transitioning alone does not affirm the trans identity, especially not in the case of Harry

whose embodiment is not the definition of his gender identity), but work both internally

and within culture to transform the meanings of the signs that demarcate any identity, and

in particular gender identity, which is based on a trenchant system of signs and cultural

values. Salamon continues, "An identity is not quite secured by the specificity of the materiality of the body, nor by a particular mental quality, but is something involving both. It can be thought by itself, yet it has been unnameable" (65). In other words, the experience of being between the gender binary and undertaking the labor to configure and affirm one's own relationship to gender is an ongoing process of work that simulates the episodic experience, and echoes in structure the very form that The Argonauts takes.

It isn't only within the public space that Harry must assert his identity in the face of gender misunderstanding. Even after Nelson has journeyed through Harry's transition with him, there are still moments where she doesn't immediately grasp his relationship to the outside world, or how he negotiates the work required to maintain his identity. Nelson tells the story of a trans student of hers whose mother wrote a piece in the New York Times about her difficulty accepting her trans son. Nelson is outraged at the piece, its public nature and the mother's inability to immediately accept and embrace her son's 
Dunn 30

transition: "I told you I was sick of stories in the mainstream media told by comfortably cisgendered folks - presumably 'us' - expressing grief over the transitions of others, presumably 'them"' (50). While Nelson expects Harry to share her feelings on the subject matter, Nelson is surprised by Harry's reaction, he raises "an eyebrow and reminded me that, just a few years ago I had expressed related fears...about the unknown changes that might be wrought by hormones, by surgery" (50). Nelson herself has forgotten that she once feared the destabilization of Harry's physical gender, feared what might change in him if he were to begin taking testosterone, but she says afterwards that really the "biggest change of all has been a measure of peace. The peace is not total, but in the face of a suffocating anxiety, a measure of peace is no small thing" (52). She goes on to say that Harry's, or really anyone's relationship to gender and embodiment, is complicated, individual, and sometimes difficult to discern, and therefore one shouldn't make assumptions about those relationships. Even Nelson can miscategorize her husband's understanding of gender (the gender of others, such as the student whose mother was publicly processing his transition, and his own gender, which Nelson herself still processes). She comes to the conclusion that "the best way to find out how people feel about their gender or their sexuality - or anything else really - is to listen to what they tell you, and try to treat them accordingly, without shellacking over their version of reality with yours" (53). In a world that Harry experiences as enacting gender upon him, the ability to listen to him, to his views on his own relationship with gender, is paramount. 
To that end, it is important to note that Harry's voice is one of the many that joins the throng of speakers in The Argonauts, setting him in the important position of helping to craft the text outside of merely his appearance as a key character. It is clear that Nelson felt it was important to represent Harry in a way that was both accurate to her experience and simultaneously not misrepresent his. Harry's voice breaks into the text at various moments, and is almost always in italics to indicate that Nelson is directly quoting his words (or at least very closely approximating them). This ability for Harry to tell part of his own story is key. Too often, trans people have their stories told for them - in the case of The Argonauts however, Harry is not only allowed his own voice, he is a part of the very editing process. Nelson presents him with a first draft of the text, hoping that Harry will both like the book and sign off on Nelson's representation of him and of their relationship:

At lunch he tells me he feels unbeheld - unheld, even. I know this is a terrible feeling. We go through the draft page by page, mechanical pencils in hand, with him suggesting ways I might facet my representation of him, of us. I try to listen, try to focus on his generosity in letting me write about him at all. He is, after all, a very private person, who has told me more than once that being with me is like a epileptic with a pacemaker being married to a strobe light artist. (46)

Harry is willing to be represented by Nelson, but it is clear that he is invested in helping to shape his own image within the text. As a person between binaries, and as a queer artist and filmmaker, this is the work that Harry has been doing his whole life - 
negotiating or helping to refine his selfhood within narrative. Even Nelson, who may arguably know Harry better than most, does not have the same relationship to his self-construction as Harry and therefore even her rendition of him in text must be negotiated between drafts.

Where Harry's voice comes in directly, Nelson takes pains to make it clear that his words are largely unedited. The longest section of Harry's storytelling differentiates itself from the rest of the text not only in italics, but in sentence structure, capitalization and tone. Harry's shorter, declarative sentences stand out against the deeply emotional content he describes, the last moments that he spends with his mother as she is dying: " $i$ told her $i$ was going to sleep, and she should too. $i$ said it firmly. i told her not to be afraid, to relax, that it was okay if she had to go. i told her $i$ knew she was tired and that all accounts of heaven (from those who have so briefly visited) are that it is pure bliss. $i$ told her not to be afraid" (130). Harry's voice is very different from Nelson's and it is clear that in these few sections (which are interspersed within Nelson's description of the painful and wondrous experience of the physical process of giving birth) his words appear in the text unedited. Harry's name appears at the margins, the same way that any of the other theorists and writers throughout the book have. Only this time there is not an intervention, reworking or reinterpretation of his thoughts from Nelson in the way that the other thinkers she deals with have been funneled through her personal experience. This unedited rendition of Harry's experience with his mother is important to letting Harry's voice tell some of his own story. After all, Nelson mentions how private Harry is multiple times over the course of the text, and therefore these words, so close to the end 
of the book and the momentous birth of Iggy are stark reminders that some experiences (like the death of Harry's mother) are not shared, not easily translatable - must be, like Harry's relationship to his gender, listened to and not assumed. As Nelson states earlier in the text, it is important to remember that there can be "difference right where we may be looking for, and expecting, communion" (93).

Though Harry's story forms just a piece of The Argonauts' overall narrative commitments, his transition and subsequent gender misrecognition are key to illustrating the larger themes of rejecting binary thinking, and laboring to create and reaffirm real, lived, identities and experiences in the space between that binary. Through the episodic suturing that the text performs, Harry's experience of reforming and reconstructing his history and his interactions with others can be communicated to a reader who is in transition themself. As The Argonauts is a text that particularly challenges narrative conventions, so it challenges its reader to piece together the meaning of the work from a multiplicity of sources, voices, moments in time, and concerns. This narrative work of making meaning from the text further cements The Argonauts as one that functions as episodic - it firmly situates the evolving reader within the trans experience. Harry's intervention into the text, in the form of direct narration and in terms of his edits and corrections to some of Nelson's assumptions, give us insight into the way in which The Argonauts' episodic structure works to further the reader's understanding of what it means to live, to really reside permanently, in a state of becoming.

If, as I have argued, Harry’s place as a nonbinary trans person situates him in a particular position between binary explanations of his gender which he has to reform in 
order to maintain his identity, The Argonauts' temporal schema also places Harry in direct relation to the narrative work that viewers do between television episodes. This narrative labor establishes a parallel between the new and evolving reader's place in the temporality of The Argonauts and Harry's. The episodic narrative places the reader in the same position as him, demonstrating what that experience of being between (between time, between genders) feels like, and the work of reconfiguration and self-narration that it requires in order to maintain legibility to oneself. Its striking resemblance to televisual time allows The Argonauts to, again, "lodge itself in the spectator, confusing the distinction between what is imaginary and what is real" (Villarejo 54). The mechanisms of The Argonauts, just as those of television, place a changing reader in direct relation to the evolving and constructing process of identity formation that is the nonbinary experience. While it is true that the new reader's felt connection to the content (i.e. Harry's relationship to gender) may be tenuous, as "Synchronization is never total, and access to prosthetic lifeworlds involves particular engagements that aren't always identificatory" (80) it is similarly true that the techniques of form, and especially time, within The Argonauts place Harry and the reader in parallel positions in a way that is both politically generative and personally transformative.

\section{Conclusion}

Sandy Stone has suggested that the state of the trans body is a particular form of genre-making, one which transgender people are not constituted "as a class or problematic 'third gender,' but rather as a genre - a set of embodied texts whose potential 
Dunn 35

for productive disruption of structured sexualities and spectra of desire has yet to be explored" (165). While this may have been true when Stone wrote her "Posttransexual Manifesto" in 1992, texts like The Argonauts are beginning to do that necessary exploration, the kind of exploration that situates trans people and their queer families not as points on a spectrum but as discrete individuals with lives with real, complicated, personal relationships to gender, normativity, and time. In a cultural moment of visibility like the one that trans people are currently experiencing, in which their stories are being told in a variety of forms, genres, and by a variety of authors, both queer and not, it is important to understand the mechanisms by which powerful representations of their lives can be achieved. The Argonauts does more than take a trans subject as one of its chief concerns, it embraces formulaic and structural elements that bring trans narrativity to the core of its construction.

This exploration necessitates a dedication to the opening of genre forms, of gesturing to an evolving set of readers and reading practices that draw on the structural elements of media like television and the digital that are being used in the contemporary landscape to tell the stories of trans and queer people. Nelson's commitment is to becoming, to allowing for the non-radical, the polyvocal, the non-normative embodiment. Nelson's use of whitespace, theoretical texts, personal experience and a timeline that never runs straight, not only allows her to gesture to alternative forms of lived time and experience, but reproduces the sensation of forming and reconstructing identity, especially in the face of a life filled with cisheteronormative misrecognitions. In its commitment to intermediality, to representing a temporality that is simultaneously a new 
kind of queer and trans time as well as one that mirrors the temporality of television, Nelson's work associates itself with the TV presentations of trans characters that have become so culturally visible recently, such as those in the hit television shows Orange is the New Black and Transparent.

Orange is the New Black and Transparent both find their homes on television streaming services that fundamentally shape the way in which their narratives are experienced by the reader $(O I T N B$ can be found on Netflix and Transparent on Amazon Prime's video streaming service). Streaming television is fundamentally different from broadcast television in several ways, one the most dramatic of these being the availability of entire seasons at once, leading to the prevalence of binge-watching these shows. Netflix itself has changed our conceptions of these medium-specific complexities to the point that

if television is defined less through the technology used and more through for- mats (particularly, it seems, the format of serialised drama) and we can schedule it ourselves, then the way to ask for our attention changes significantly. In other words, increasingly complex narrative structures demand our attention in a way scheduled television rarely can (Mareike 269).

The emphasis on season-long plot lines, more complexity in the stories of individual characters and more intricately altered timelines are possible when the narrative arc of a streaming-service television show is conceptualized around the season rather than around the episode. These "changes around television are also part of a larger conceptual shift 
across all media, as the aesthetic, technological, industrial and cultural boundaries between previously discrete forms (text, film, broadcasting, video, and sound recordings) are increasingly blurred, challenging established practices and paradigms" (Kompare 198).

It is perhaps not coincidental that a multiplicity of trans and queer stories are being told precisely at the moment that television models, restrictions, and forms are changing, after all those "borders that exist at the levels of technology/industry/mode of address" often "appear to have inspired or enabled an attention to spatial/social/historical borders" (Williams 47). If these borders of media are changing, or even dissolving, then it is interesting to note the ways in which streaming shows begin to address those characters that lie outside of normative frameworks - especially queer and trans characters. The transgender characters of Sophia from Orange is the New Black and Maura from Transparent are undoubtedly profoundly influenced by their representation in a fundamentally visual media. Indeed both are often pictured in front of a mirror and the physical display of their transitions (Sophia's in flashback and Maura's over the course of the show) hold considerable cultural power. But how can these representations take on new significance when viewed with special consideration for their shows' participation in episodic temporality, a temporality that is evolving along with the transformation of television itself? What does it mean to read these televisual (with an emphasis on the visual) stories of trans people with an eye towards the destabilizing media movements that they invest in and to what extent does the trans character embody, demonstrate, or reconstruct these movements? 
There has perhaps never been a more crucial moment for trans theorists and critics to produce and interrogate the theory that powers the structuring and understanding of trans identity, but while doing so it is imperative that we continue to honor the personal, the affective, the familial and the queer that makes up the aggregated experience of those identities. As Kate Drabinski argues in her article on female to male narratives: "The body, and how we tell stories about the bodies in which we live, is itself a point of critical departure for thinking about subjectivity, selfhood, and, ultimately, freedom not in the sense of final liberation, but in the sense of living differently, in multiplicities" (Drabinski 314). Nelson's revolutionary commitment to structuring The Argonauts with the white space that makes it an episodic story allows her work to exist within an ecosystem of changing media. The text therefore takes part in opening that media space for the confirmation and transmission of Nelson and Harry's lived resistance to binary labels, identifications, and familial formations. Her text approaches temporality as a way to transcend definitions of strict media and genre coherence, defined by Mary Ann Doane as “both [a medium's] positive qualities (the visibility, color, texture of paint, for instance) and its limitations, gaps, incompletions (the flatness of the canvas, the finite enclosure insured by the frame)" (Doane 130).

Nelson's genre-bending book does not rehearse the most powerful theories of transgender theory, whether by Jack Halberstam, Judith Butler, or others, and yet is not possible to imagine Nelson's work in the absence of this important theory. However, by situating itself within a family tale, The Argonauts becomes a work of composite art and criticism that accomplishes something more akin to Claudia Rankine's Citizen, as Citizen 
won awards as both a work of poetry and of critical theory. The power of The Argonauts is that as a work that transcends genre and provides a theoretical framework for the force of affect and personal experience within Nelson and Harry's lives, it can shed light on our own critical stances just as it offers another kind of transgender narrativity and a fresh look at the radical forms of relation that are queer family-making.

Finally, The Argonauts' blending of theory and personal experience leads us to consider our own experiences within the lenses of theoretical discourse, encouraging us as scholars and media consumers to think of theorists and writers (like Nelson herself) as part of an extended queer family. The Argonauts calls us to document, to embrace our own forms of uncategorizable identities, and to be open to listening to those of others. "One question that remains unanswered in the queer scholarly debate about futurity," Elizabeth Freeman writes, "is why write? This is a temporal question and a sexual one, if not obviously so. One answer might be that writing refigures both spatial and temporal relations in ways that feel queer." (168) Another answer might be that writing, especially the kind of writing that Nelson does in The Argonauts is about making sense of queer lives that are at once transformatively political, desperately personal, and exceedingly powerful in their very resistance to easy categorization. If "writerly strategies are ways to throw something out into a formless future, disseminating the self in the hopes that someone, someday, might reassemble the pieces in ways that in turn reconfigure his or her own present, or rearrange our sense of the past" (Freeman 168) then Nelson's work writes her experience into queer history and family, and in turn, my discussion has attempted to reassemble The Argonauts' pieces. 


\section{Works Cited}

Drabinski, Kate. "Incarnate Possibilities: Female to Male Transgender Narratives and the Making of Self." Journal of Narrative Theory 44.2 (2014): 304-29. Web.

Duggan, Lisa. "The New Homonormativity: The Sexual Politics of Neoliberalism." Materializing Democracy: Toward a Revitalized Cultural Politics. Ed. Russ

Castronovo and Dana D. Nelson. Durham: Duke UP, 2002. N. pag. Print.

Freeman, Elizabeth. "Introduction." GLQ: A Journal of Lesbian and Gay Studies 13.2-3 (2007): 159-76. Web.

Halberstam, Judith. In a Queer Time and Place: Transgender Bodies, Subcultural Lives. New York: New York UP, 2005. Print.

HRC Addressing Anti-Transgender Violence. Human Rights Campaign, 1 Nov. 2015.

Web. 4 Apr. 2016.

Jenner, Mareike. "Is This TVIV? On Netflix, TVIII and Binge-watching." New Media \& Society 18.2 (2014): 257-73. Web.

Kompare D (2005) Rerun Nation: How Repeats Invented American Television. New York: Routledge.

Muñoz, José Esteban. Cruising Utopia: The Then and There of Queer Futurity. New York: New York UP, 2009. Print.

Nelson, Maggie. The Argonauts. Minneapolis: Graywolf, 2015. Print.

"Non-Discrimination Laws." NCTE State Nondiscrimination Map. National Center for 
Transgender Equality, 30 Jan. 2015. Web. 14 Apr. 2016.

$<$ http://www.transequality.org/issues/resources/map-state-transgender-non-discri mination-laws $>$.

Salamon, Gayle. Assuming a Body: Transgender and Rhetorics of Materiality. New

York:

Columbia UP, 2010. Print.

Steinmetz, Katy. "The Transgender Tipping Point." Time Magazine 29 May 2014: n.

Pag.

Print.

Stone, Sandy. "The Empire Strikes Back: A Posttranssexual Manifesto." Camera Obscura: Feminism, Culture, and Media Studies 10.229 (1992): 150-76. Web. Villarejo, Amy. Ethereal Queer: Television, Historicity, Desire. Durnham: Duke UP, 2014. Print.

Weiner, J. J., and D. Young. "Introduction: Queer Bonds." GLQ: A Journal of Lesbian and Gay Studies 17.2-3 (2011): 223-41. Web.

Williams, Mark. 2009. “'Rewiring Media History: Intermedial Borders.” In Staiger and Hake, Convergence Media History, 46-56. 